\title{
DESKRIPSI DAN ANALISIS PROSPEK KOMODITI KELAPA DI SULAWESI UTARA DENGAN ANALISIS MATRIKS SWOT
}

\author{
Ronaldo F.I Rottie \\ Program Studi Teknik Industri, Fakultas Tekinik, Unika De La Salle Manado \\ e-mail: aldorottie@gmail.com
}

\begin{abstract}
Abstrak
Kebutuhan produk kelapa bagi masyarakat Indonesia setiap tahunnya meningkat sejalan dengan pertumbuhan jumlah penduduk. Sehingga diperkirakan kebutuhan ini juga akan terus meningkat pada masa yang akan datang dimana mengingat pola hidup masyarakat Indonesia ke depan yang tidak dapat dilepaskan dari kelapa dan produk olahannya. Oleh karena itu perlu mengarahkan pengembangan produk olahan pada produk baru sehingga permintaan pasarnya cenderung meningkat (demand driven). Dengan demikian perlu diketahui bagaimana pengembangan industri kelapa Indonesia dengan potensi komoditi Kelapa di Sulawesi Utara. Dengan menggunakan metode SWOT akan dijabarkan deskripsi dari prospek komoditi kelapa di Indonesia khususnya di Sulawesi Utara. Dengan menggunakan metode SWOT kita menganalisis faktor internal dan eksternal dengan analisis pada Internal Strategic Factor Analysis Summary (IFAS) dan analisis pada External Strategic Factors Analysis Summary (EFAS).
\end{abstract}

Kata kunci: Metode SWOT, IFAS, EFAS.

\section{Abstrak}

Requirement of coconut product for Indonesia society every year it's increases in line with growth of number of residents. So is estimated this requirement also would continuously increase during which will come where considering Indonesia public life pattern forwards which cannot be discharged from the coconut and processing result. Therefore need to point product development of processing to new product so that request of the market tends to increase (demand driven). Thereby it is important to know how industrial expansion of Indonesian coconut with coconut commodity potency in North Sulawesi. By using method SWOT will be formulated description from coconut commodity prospect in Indonesia especially in North Sulawesi. By using method SWOT we are internal factor analysis and eksternal with analysis at Internal Strategic Factor Analysis Summary (IFAS) and analysis at External Strategic Factors Analysis Summary ( EFAS).

Keyword: SWOT Method, IFAS, EFAS.

\section{Pendahuluan}

Kebutuhan produk kelapa bagi masyarakat Indonesia setiap tahunnya meningkat sejalan dengan pertumbuhan jumlah penduduk. Sehingga diperkirakan kebutuhan ini juga akan terus meningkat pada masa yang akan datang dimana mengingat pola hidup masyarakat Indonesia ke depan yang tidak dapat dilepaskan dari kelapa dan produk olahannya.

Disamping itu, dengan semakin tingginya harga minyak bumi, maka minyak kelapa dapat dimanfaatkan untuk substansi energi khususnya solar. Substitusi solar dari minyak kelapa memungkinkan khususnya untuk daerah-daerah terpencil sentra kelapa.

Permintaan pasar ekspor produk olahan kelapa umumnya menunjukan trend yang meningkat. Sebagai contoh, desicated coconut Indonesia terhadap ekspor $D C$ dunia cenderung meningkat dalam lima tahun terakhir. Kecenderungan yang sama terjadi pada arang aktif. Sebaliknya pangsa ekspor crude coconut oil (CCO) mengalami penurunan. Situasi ini mengisyaratkan perlunya mengarahkan pengembangan produk olahan pada produk-produk baru yang permintaan pasarnya cenderung meningkat (demand driven).

Industri pengolahan komponen buah kelapa tersebut umumnya hanya berupa industri tradisional dengan kapasitas industri yang masih sangat kecil dibandingkan potensi yang tersedia sehingga seringkali hasil produksi tidak bisa memenuhi permintaan pasar.

\section{Tinjauan Pustaka}

\subsection{Analisis SWOT}

SWOT adalah singkatan yg diambil dari huruf depan kata Strength, Weakness, Opportunity dan Threat, yg dalam bahasa Indonesia mudahnya diartikan sbg Kekuatan, Kelemahan, Peluang dan Ancaman.

Analisis SWOT adalah metode perencanaan strategis yang digunakan untuk mengevaluasi kekuatan, kelemahan, peluang, dan ancaman dalam suatu proyek atau suatu spekulasi bisnis. Proses ini melibatkan penentuan tujuan yang spesifik dari spekulasi bisnis atau proyek dan mengidentifikasi faktor internal dan eksternal yang mendukung dan yang tidak dalam mencapai tujuan tersebut. Hasil analisa biasanya adalah arahan/rekomendasi untuk mempertahankan kekuatan dan menambah keuntungan dari peluang yang ada, sambil mengurangi kekurangan dan menghindari ancaman. $\mathbf{S}$ dan $\mathbf{W}$ mengidentifikasikan kekuatan dan kelemahan internal perusahaan dalam hal ini berkaitan dengan fungsi manajemen (perencanaan, pengorganisasian, pengarahan, pemberian motivasi dan pengendalian). $\mathrm{S}$ dan $\mathrm{W}$ juga mengidentifikasi kekuatan dan kelemahan pada fungsi bisnis. Sedangkan $\mathbf{O}$ dan $\mathbf{T}$ 
merupakan analisis eksternal, berupa peluang dan ancaman yang meliputi aspek : sosial, teknologi, ekonomi, politik, hukum, lingkungan, demografi dan pesaing. Dalam analisis matriks SWOT diterapkan sistem bobot, nilai (rating) dan skoring untuk unsur-unsur yang dianggap penting. Faktor-faktor internal dan eksternal diberi bobot dengan skala mulai dari 0 sampai dengan 1 dengan jumlah keseluruhan faktor internal yang terdiri dari kekuatan dan kelemahan adalah 1, begitu juga untuk faktor eksternal yang terdiri dari peluang dan ancaman. Selanjutnya penerapan sistem nilai (rating), nilai rating berkisar antara 1 sampai 4 :

- 4 = respons sangat bagus / peluang paling besar / ancaman paling kecil

- 3 = respons diatas rata-rata / peluang besar / ancaman kecil

- 2 = respons rata-rata / peluang kecil / ancaman besar

- 1 = respons dibawah rata-rata / peluang paling kecil / ancaman paling besar. [1]

\subsection{Tahapan-Tahapan Analisis SWOT}

Tahapan-Tahapan Analisis SWOT yaitu:

- Identifikasi faktor internal dan external, yang mana dilakukan analisis pada Internal Strategic Factor Analysis Summary (IFAS) termasuk didalamnya kekuatan (strength) dan kelemahan (weakness), yang kemudian analisis pada External Strategic Factors Analysis Summary (EFAS) termasuk didalamnya peluang (opportunity) dan ancaman (threat).

- Membuat tabel analisis faktor internal dan ekstenal dan sekaligus dilakukan sistem bobot, rating, skoring dan total skor.

- Membuat matriks general eletric untuk melihat suatu kegiatan industri tersebut dapat berkembang dengan strategi yang tepat sesuai dengan total skor yang berasal dari tabel analisis faktor internal dan eksternal. Pada tahapan ini, perkembangan dikelompokkan kedalam 9 bagian yaitu penciutan melalaui 'turn around, divestasi, likuidasi, pertumbuhan melalui integrasi horizontal, penggabungan dari pertumbuhan integrasi horizontal dan stabilitas, pertumbuhan melalui diversifikasi konglomerat, pertumbuhan melalui integrasi vertikal, stabilitas dan yang terakhir adalah pertumbuhan melalui diversifikasi konsentrik.

- Membuat analisis dengan menggunakan analisis matriks SWOT. Metode ini meninjau pemecahan masalah yang dibagi kedalam pemecahan masalah strategi strength dan opportunity (SO), strategi weakness dan opportunity (WO), strategi strength dan threath, juga antara weakness dan threath (WT).

\subsection{Proses Analisis}

Kegiatan yang paling penting dalam proses analisis adalah memahami seluruh informasi yang terdapat pada suatu kasus, kemudian menganalisis situasi untuk menggambarkan situasi yang terjadi dan memutuskan apa tindak lanjut dalam pemecahan masalah. [2] Proses untuk melaksanakan analisis suatu kasus dapat dilihat dalam diagram Proses analisis kasus.

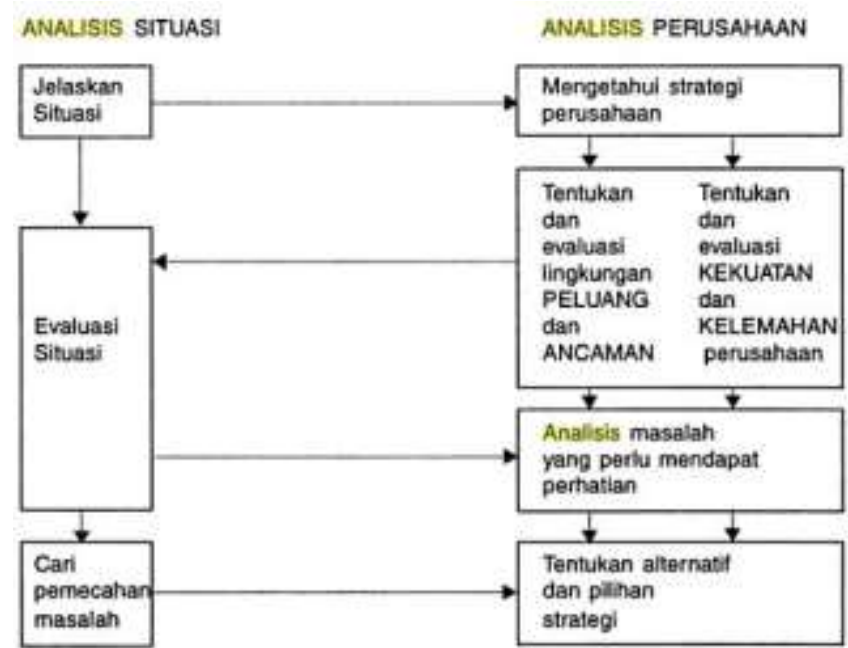

Gambar 1. Diagram Proses Analisis Kasus (Sumber: [2])

\section{ANALISIS \& PEMBAHASAN}

\subsection{Prospek Industri Kelapa di Sulut}

Sebagai salah satu Sebagai salah satu daerah penghasil kelapa yang potensial,SULUT memiliki beberapa areal perkebunan kelapa yang disini berdasarkan data BPS terbagi atas:

- Perkebunan besar negara dan swasta dengan luas areal yang produktif sekitar 9.469,01 ha,

- Perkebunan rakyat seluas 212.081,13 ha,dan

- Perkebunan besar/rakyat produktif seluas 214.767,55 ha (ini belum termasuk luas areal yang belum menghasilkan).

Dengan luas area tanam sebesar ini,sekarang SULUT telah memiliki 35 anak perusahaan yang mengelola komoditi kelapa sektor kecil-menegah.

Dengan jenis Indutri pengolahan Kelapa yang dihasilkan di Sulut adalah sebagai berikut:

\begin{tabular}{|c|c|c|}
\hline Jenis Industri & $\begin{array}{c}\text { Kapasitas Produksi } \\
\text { (Ton/Tahun) }\end{array}$ & $\begin{array}{c}\text { Tenaga Kerja } \\
\text { (orang) }\end{array}$ \\
\hline Minyak Kelapa & 190.260 & 5.086 \\
Minyak Goreng & 137.100 & 1.043 \\
Tepung Kelapa & 7.224 & 1.904 \\
Kopra & 246.000 & 7.000 \\
Arang Tempurung & 4.766 & 1.000 \\
Karbon Aktif & 7.200 & 150 \\
Sabut Kelapa & 15.800 & 308 \\
VCO & 6.000 & 1.000 \\
\hline
\end{tabular}

Tabel 1. Jenis Industri Kelapa di SULUT

(Sumber: Disperindag SULUT,Klaster Kelapa 2006, BPS

[4]) 


\subsection{Analisis Faktor Strategi}

1. Analisis IFAS dapat dilihat dala tabel berikut ini:

\begin{tabular}{|c|c|c|c|}
\hline Faktor Strategi Internal & Bobot & Rating & Skor \\
\hline \multicolumn{4}{|l|}{ Kekuatan } \\
\hline $\begin{array}{l}\text { SULUT merupakan salah satu } \\
\text { daerah sentra komoditi kelapa } \\
\text { dan berada pada urutan ke tiga }\end{array}$ & 0.18 & 4 & 0.72 \\
\hline $\begin{array}{l}\text { Kelapa di SULUT merupakan } \\
\text { komoditi primer dari sector } \\
\text { pertanian dengan luas areal } \\
\text { lebih dari } 400000 \text { ha }\end{array}$ & 0.18 & 4 & 0.72 \\
\hline \multicolumn{4}{|l|}{ Kelemahan } \\
\hline $\begin{array}{l}\text { Produktivitas tanaman kelapa } \\
\text { yang dihasilkan rendah }\end{array}$ & 0.18 & 3 & 0.54 \\
\hline Tingkat harga yang berfluktuasi & 0.17 & 3 & 0.51 \\
\hline $\begin{array}{ll}\begin{array}{l}\text { Kurangnya } \\
\text { ekonomi }\end{array} & \text { kelembagaan } \\
\end{array}$ & 0.06 & 2 & 0.12 \\
\hline $\begin{array}{l}\text { Pada umumnya } \\
\text { tanaman sudah tua dan rusak }\end{array}$ & 0.09 & 3 & 0.27 \\
\hline Minimnya teknologi on-farm & 0.04 & 2 & 0.08 \\
\hline Kurangnya infrastruktur jalan & 0.05 & 1 & 0.05 \\
\hline \multirow[t]{2}{*}{ Tidak ada payung hokum } & 0.05 & 1 & 0.05 \\
\hline & 1.00 & & 3.06 \\
\hline
\end{tabular}

Tabel 2. Tabel Faktor Strategis Internal

(Sumber:Hasil Analisis \& Pembobotan)

2. Analisis EFAS dapat dilihat pada tabel berikut ini:

\begin{tabular}{|c|c|c|c|}
\hline Faktor Strategi Eksternal & Bobot & Rating & Skor \\
\hline \multicolumn{4}{|l|}{ Peluang } \\
\hline $\begin{array}{l}\text { Posisi Provinsi SULUT yang } \\
\text { prospektif secara } \\
\text { maupun internasional }\end{array}$ & 0.18 & 4 & 0.72 \\
\hline $\begin{array}{l}\text { Potensi SULUT sebagai pusat } \\
\text { pertumbuhan ekonomi dalam } \\
\text { AFTA }\end{array}$ & 0.18 & 4 & 0.72 \\
\hline \multicolumn{4}{|l|}{ Ancaman } \\
\hline $\begin{array}{l}\text { Kurangnya jenis produk } \\
\text { tanaman kelapa yang dihasilkan } \\
\text { apabila dibandingkan dengan } \\
\text { produsen daerah lain. }\end{array}$ & 0.16 & 2 & 0.32 \\
\hline $\begin{array}{l}\text { Persaingan dengan minyak } \\
\text { nabati }\end{array}$ & 0.17 & 1 & 0.17 \\
\hline Kendala Birokrasi & 0.15 & 1 & 0.15 \\
\hline \multirow[t]{2}{*}{$\begin{array}{lcc}\text { Isu } & \text { kesehatan mengenai } \\
\text { Standar Faktor Aflatoksin }\end{array}$} & 0.16 & 3 & 0.48 \\
\hline & 1.00 & & 2.56 \\
\hline
\end{tabular}

Tabel 3. Faktor Strategis Eksternal

(Sumber:Hasil Analisis \& Pembobotan)

\subsection{Analisis Matriks General Electric}

Dengan menggunakan total skor dari tabel analisis faktor internal dan eksternal, dapat ditentukan posisi dari perusahaan industri kecil-menengah untuk komoditi kelapa di Sulawesi Utara dengan matriks General Electric seperti di bawah ini:

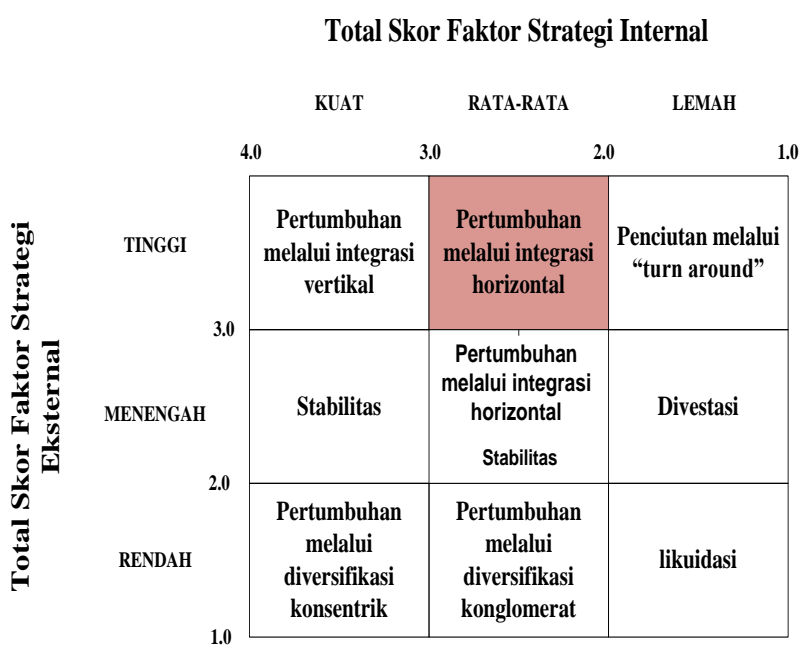

Gambar 2. Matriks General Electric

(Sumber: Hasil Analisis)

Dengan strategi pertumbuhan melalui integrasi horizontal, maka perusahaan-perusahaan ikan menengah kecil yang ada di Sulut dapat memperluas pasar, penambahan fasilitas produksi dan teknologi melalui pengembangkan internal dan eksternal. Kegiatan yang dapat dilakukan adalah dengan joint ventures dengan perusahaan lain dalam industri yang. Strategi ini bertujuan relatif defensive, dimana dapat menghindari kehilangan penjualan dan kehilangan profit.

\subsection{Analisis Matriks SWOT}

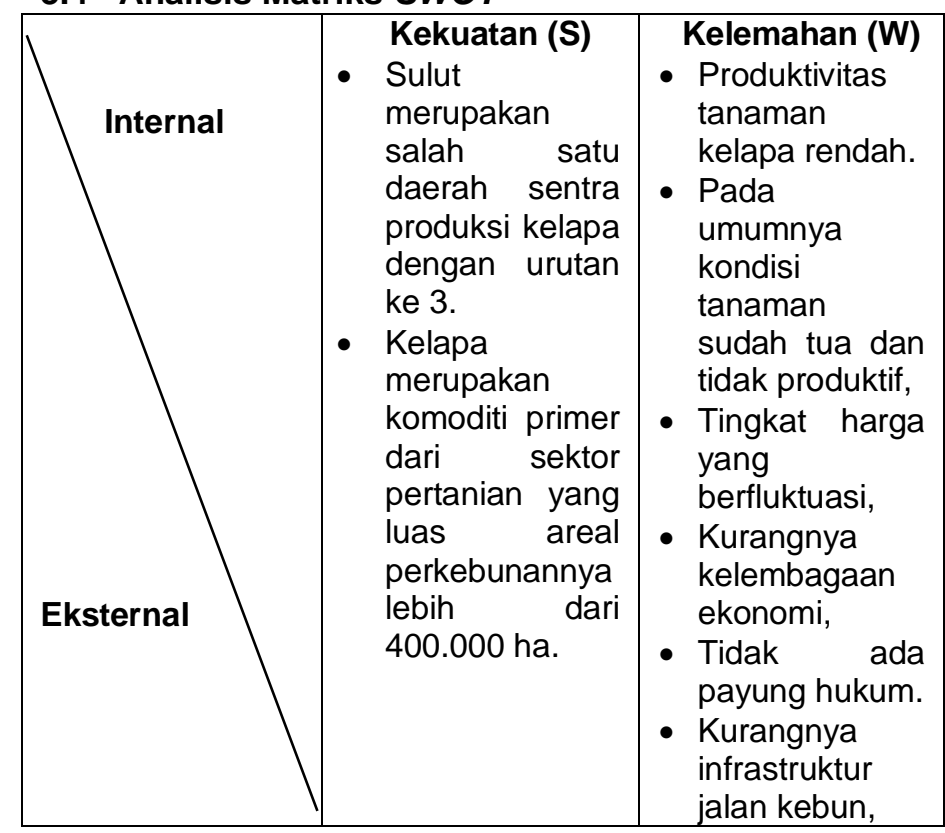




\begin{tabular}{|c|c|c|}
\hline $\begin{array}{l}\text { Peluang (O) } \\
\text { - } \text { Potensi } \\
\text { SULUT } \\
\text { sebagai pusat } \\
\text { pertumbuhan } \\
\text { ekonomi } \\
\text { dalam AFTA. } \\
\text { - Posisi SULUT } \\
\text { secara } \\
\text { regional } \\
\text { maupun } \\
\text { internasional } \\
\text { yang } \\
\text { prospektif }\end{array}$ & $\begin{array}{l}\text { Strategi SO } \\
\text { - Pengembangan } \\
\text { dukungan } \\
\text { kebijkan untuk } \\
\text { kredit modal } \\
\text { petani. } \\
\text { - Dukungan } \\
\text { untuk } \\
\text { pengembangan } \\
\text { teknis baik } \\
\text { melalui } \\
\text { pelatihan } \\
\text { maupun } \\
\text { teknologi on- } \\
\text { farm. }\end{array}$ & 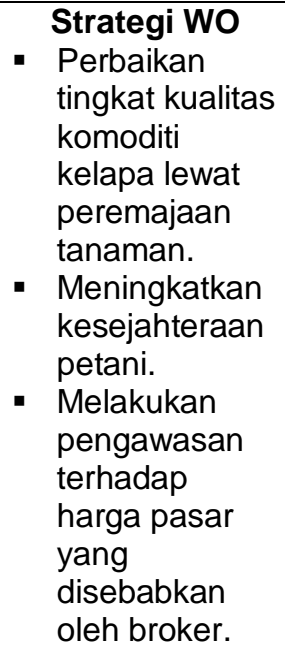 \\
\hline $\begin{array}{l}\text { Ancaman (T) } \\
\text { - Kurangnya } \\
\text { jenis tanaman } \\
\text { produk kelapa } \\
\text { yang } \\
\text { dihasilkan jika } \\
\text { dibandingkan } \\
\text { dengan } \\
\text { daerah } \\
\text { produsen lain. } \\
\text { - Persaingan } \\
\text { dengan } \\
\text { minyak nabati } \\
\text { lainnya. } \\
\text { Kendala } \\
\text { birokrasi. } \\
\text { - Isu kesehatan } \\
\text { mengenai } \\
\text { Standar } \\
\text { Faktor } \\
\text { Aflatoksin. }\end{array}$ & $\begin{array}{l}\text { Strategi ST } \\
\text { Meningkatkan } \\
\text { fariasi hasil } \\
\text { olahan } \\
\text { komoditi lewat } \\
\text { kerjasama } \\
\text { dengan balai } \\
\text { penelitian } \\
\text { kelapa. } \\
\text { Mengurangi } \\
\text { kelalaian } \\
\text { produksi akibat } \\
\text { kendala } \\
\text { birokrasi. }\end{array}$ & $\begin{array}{l}\text { Strategi WT } \\
\text { Mengawasi } \\
\text { pengolahan } \\
\text { kelapa dari } \\
\text { sektor } \\
\text { kesehatan. }\end{array}$ \\
\hline
\end{tabular}

\section{KESIMPULAN DAN SARAN}

4.1 Kesimpulan

Berdasarkan hasil analisis masalah yang telah dilakukan,maka dapat disimpulkan bahwa:

1. Sulut memiliki luas areal perekebunan kelapa lebih dari 400.000 ha dengan jumlah industri kecil menengah sebanyak 35 perusahaan.

2. Luas areal tanaman kelapa selama 10 tahun terakhir mengalami pertumbuhan yang sangat lambat, sehingga menyebabkan untuk tahun-tahun mendatang kecenderungan akan terjadi kekurangan pasokan kelapa.Pertumbuhan yang lambat ini disebabkan karena sebagian besar perkebunan diusahakan secara monokultur dengan penerapan teknologi yang belum utuh.

3. Khusus untuk minyak kelapa,persaingan dengan minyak nabati lainnya seperti kelapa sawit telah menekan pengembangan tanaman kelapa.

4. Sebagian masalah yang ada selama ini timbul dari kurangnya pengetahuan para petani dalam mengembangkan produktivitas kelapa.

5. Selain digunakan dalam industri kosmetik dan pangan,ternyata minyak kelapa dapat dimanfaatkan juga untuk substansi energi khususnya solar.

6. Lewat analisis SWOT diketahui bahwa Prospek Komoditi Kelapa untuk tahun ke depan akan bias menjadi lebih maju dengan dilakukan peningkatan pertumbuhan melalui integrasi horizontal.

\subsection{Saran}

Dari hasil analisa masalah dan berdasarkan tujuan penelitian sebelumnya,maka saran yang dapat kami berikan untuk mengembangkan prospek komoditi kelapa di SULUT adalah:

1. Perlu segera dilakukan peremajaan terhadap tanaman yang telah tua dan rusak.

2. Disediakan dukungan kebijakan untuk usaha tani, yaitu disini adalah penyediaan kredit modal dan pembinaan teknis.

3. Dilakukan kerjasama dengan Balitka untuk penelitian lebih lanjut mengenai pengembangan pengolahan kopra sebagai alternatif untuk substitusi bahan bakar biodiesel.

4. Kendala birokrasi yang disebabkan oleh para broker diminimalkan agar tidak terjadi fluktuasi harga yang terlalu menyolok sehingga keadaan pasar dapat terkendali.

\section{DAFTAR PUSTAKA}

[1] John A, Pearce II, Richard B Robinson Jr Manajemen Strategis. 2008. Jakarta: Salemba Empat

[2] Rangkuti Freddy. 2006. Analisis SWOT Teknik Membedah Kasus Bisnis, Jakarta: PT.Gramedia Pustaka Utama. Cetakan 14

[3] Assauri Sofjan. Manajemen Pemasaran; Dasar, Konsep dan Strategi.1996. Jakarta:Rajawali Pers

[4] Badan Pusat Statistik Provinsi Sulawesi Utara: "Sulawesi Utara Dalam Angka 2008"

[5] Data Informasi Dinas Perindustrian dan Perdagangan Sulawesi Utara 